Original Article

\title{
Characteristics of coping strategies and the relationships between coping strategies and stress reactions in physical therapy students during clinical practice
}

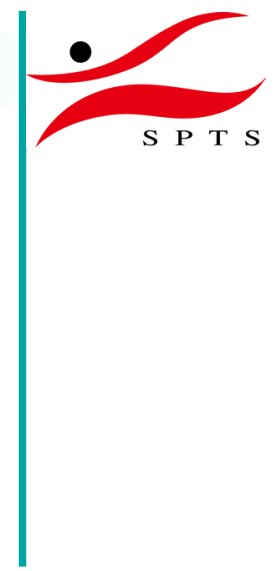

\author{
Daisuke Higuchi, $\mathrm{PhD}^{1)^{*}}$, Ayumi Echigo, $\mathrm{MS}^{2)}$ \\ 1) Department of Physical Therapy, Takasaki University of Health and Welfare: 501 Nakaorui-machi, \\ Takasaki-shi, Gunma 370-0033, Japan \\ 2) Department of Physical Therapy, Tohoku Medical College, Japan
}

\begin{abstract}
Purpose] The aim of the present study was to understand the coping strategies used during physical therapy clinical practice. [Subjects and Methods] Sixty-eight of 77 physical therapy students (88.3\%) responded to questionnaires, including a tri-axial coping scale and a scale of stress reactions after clinical practice (median age=22 years; 45 were male, 23 were female; 37 third-year students, 31 fourth-year students). The scores of males and females were compared via descriptive statistics. In addition, stepwise logistic regression analysis was performed. Dummy variables were created based on the median scores of stress reactions $(0=$ slight reactions; $1=$ severe reactions), and were used as the dependent variables. [Results] The stress reaction scores of female (median score $=7$ points) were significantly higher than those of male students (5 points). The following significant logistic regression equation was obtained: $\log (\mathrm{p} /(1-\mathrm{p}))=1.78+1.96$ [gender $(0=$ male; $1=$ female $)]+0.30$ (buck passing strategy). The odds ratios for gender and buck passing were 7.12 and 1.34, respectively. [Conclusion] Clinical practice educators should be aware that female students and those that use buck passing are more likely to suffer from severe stress reactions during physical therapy clinical practice.

Key words: Physical therapy students, Coping strategies, Clinical practice
\end{abstract}

(This article was submitted Apr. 20, 2016, and was accepted Jun. 27, 2016)

\section{INTRODUCTION}

Medical students face various stressors, including academic issues ${ }^{1-4)}$. Physical therapy students (PTSs) may encounter academic stressors during clinical practice. PTSs engage in clinical practice to improve their physical therapy skills at medical and welfare facilities in Japan (i.e., not at their schools). In addition, PTSs provide physical therapy under the guidance and support of physical therapists working in the facilities (i.e., not their teachers). These learning environments surrounding clinical practice may influence PTSs. Yoshida et al. reported that the degree of anxiety and the activation of $\alpha$-amylase in the saliva of PTSs after clinical practice were greater than those before clinical practice ${ }^{5}$. In addition, Matsumoto et al. reported that the degree of fatigue and the blood level of adrenocorticotropic hormone after clinical practice were greater than before clinical practice ${ }^{6}$.

Lazarus posited a transactional model of stress in which the cognitive processes for stress mediate the relation between stressors and stress reactions ${ }^{7}$. The cognitive processes include estimation of the value of stressors and selection of coping strategies to cope with stressors. This model explains why stress reactions differ across different persons, even when they are exposed to similar stressors. It is possible that the stress reactions of PTSs resulting from clinical practice can be reduced

\footnotetext{
*Corresponding author. Daisuke Higuchi (E-mail: higuchi-d@takasaki-u.ac.jp)

(C)2016 The Society of Physical Therapy Science. Published by IPEC Inc.

This is an open-access article distributed under the terms of the Creative Commons Attribution Non-Commercial No Derivatives (by-nc-nd) License $<$ http://creativecommons.org/licenses/by-nc-nd/4.0/>.
} 
by either changing thoughts about clinical practice or developing coping strategies for problems associated with clinical practice.

There are three traditional classifications of coping strategies: approach and avoidance strategies, problem- and emotionfocused coping strategies, and behavioral and cognitive strategies. The tri-axial coping scale (TAC-24) combines these three classifications and yields the following eight coping strategies: information gathering (IG; approach, problem-focused, and behavioral strategies), giving up (GU; avoidance, problem-focused, and cognitive strategies), affirmative interpreting (AI; approach, emotion-focused, and cognitive strategies), planning (PL; approach, problem-focused, and cognitive strategies), evasive thoughts (ET; avoidance, emotion-focused, and cognitive strategies), diversion (DI; avoidance, emotion-focused, and behavioral strategies), catharsis (CA; approach, emotion-focused, and behavioral strategies), and buck passing (BP; avoidance, problem-focused, and behavioral strategies). The TAC-24 is a reliable tool for assessing coping strategies for stressors associated with clinical practice.

Kamimura et al. ${ }^{8)}$ reported that there was an increase in the frequencies of positive problem-solving, help-seeking and diversion strategies during clinical practice. Tateishi et al. ${ }^{10)}$ reported that the frequency of using emotion-focused coping strategies was twice as great as that of problem-focused coping strategies among occupational therapy students completing clinical practice. However, the characteristics of the coping strategies of PTSs coping strategies during clinical practice are unclear.

Therefore, in the present study, we investigated the use of coping strategies associated with the stress of clinical practice and the relations between coping strategies and stress reactions among PTSs. This study was conducted to understand the coping strategies used during physical therapy clinical practice.

\section{SUBJECTS AND METHODS}

This cross-sectional study was conducted in September 2014 and December 2014 at a 4 year vocational college of physical therapy in Japan. The study was conducted after approval was obtained from the Ethics Committee of Takasaki University of Health and Welfare (No. 2615).

Students in their third and fourth years of a physical therapy program at a vocational college participated. All participants had completed clinical practice within 1 week of participation. All participants provided written consent for participation after they were provided with a sufficient explanation of the present study. The clinical practice for third-year students provided experience relating to performance of assessments in physical therapy, including interpretation and integration of results obtained. The goal of clinical practice for fourth-year students was to give students the opportunity to plan and provide physical therapy. The durations of clinical practice for third- and fourth-year students were 5 and 16 weeks, respectively. Clinical practice was completed under the direction of physical therapists who worked in either the medical or welfare facilities.

TAC-249) was used, and the expository writing of the TAC-24 was partially modified to investigate past use of coping strategies for "stressors associated with clinical practice." Because the original TAC-24 assesses current behaviors and thoughts about daily stress, the scale used herein was approved by a chief developer of the TAC-24. The reliability coefficient of the modified TAC-24 was acceptable (Cronbach's $\alpha=0.73)^{11)}$.

The TAC-24 consists of eight coping strategies (see the detailed description in the introduction section). The scores of each coping strategy range from 3 to 15 points, with higher scores indicating a greater use of coping strategies. In addition, an 11 -point numerical rating scale (NRS) $(0=$ no stress reactions, $10=$ unbearable stress reactions) was used to assess the degree of perceived stress reactions during clinical practice.

First, descriptive statistics were computed for all variables of interest. Participants were divided into two groups based on gender and year of study. Mann-Whitney's U test was used to compare the two groups. Second, Spearman's correlation coefficients were computed between the coping strategy scores of the TAC-24 and the NRS score of stress reactions. Age, gender $(0=$ men, $1=$ females $)$, and year of study $(0=$ third year, $1=$ fourth year $)$ were controlled for in the correlational analysis. Moreover, stepwise logistic regression analysis was performed. Binary dummy variables were computed based on the median NRS score [ $0=$ slight stress reactions group (less than the median NRS score), $1=$ severe stress reactions group (median NRS score or more)] and were used as dependent variables. Age, gender, year of study, and the coping strategy scores that were significantly correlated with the NRS score were the independent variables. All statistical analyses were performed using HAD version $13^{12)}$. Values of $\mathrm{p}<0.05$ were statistically significant.

\section{RESULTS}

Sixty-eight of 77 PTSs completed the questionnaires (response rate, 88.3\%). The median and quartile deviation for age of participants were 22 and 0.5 years, respectively (range, 20-41 years). Forty-five participants were male (66.2\%), and 37 participants were third-year students $(54.4 \%)$.

The descriptive statistics for the variables of interest are shown in Table 1. Spearman's correlation coefficients are summarized in Table 2. The scores for the GU, AI, and BP strategies were used as independent variables in the stepwise logistic regression analysis. Thirty-one PTSs $(45.6 \%)$ belonged to the slight stress reactions group (NRS $<7$ ), and the other PTSs 
Table 1. Descriptive statistics for the variables of interest

\begin{tabular}{|c|c|c|c|c|c|c|c|c|c|c|c|c|c|c|c|}
\hline \multirow[t]{2}{*}{ Items } & \multicolumn{3}{|c|}{ All $(\mathrm{N}=68)$} & \multicolumn{3}{|c|}{ Male $(\mathrm{N}=45)$} & \multicolumn{3}{|c|}{ Female $(\mathrm{N}=23)$} & \multicolumn{3}{|c|}{ Third grade $(\mathrm{N}=37)$} & \multicolumn{3}{|c|}{ Fourth grade $(\mathrm{N}=31)$} \\
\hline & $\mathrm{M}$ & QD & Range & $\mathrm{M}$ & QD & Range & $\mathrm{M}$ & QD & Range & $\mathrm{M}$ & QD & Range & $\mathrm{M}$ & QD & Range \\
\hline \multicolumn{16}{|l|}{ Tri-axial coping scale } \\
\hline IG (3-15 points) & 9 & 2.0 & $3-15$ & 9 & 1.5 & $5-15$ & 9 & 1.5 & $3-13$ & 10 & 1.5 & $3-14$ & 9 & 1.8 & $3-15$ \\
\hline GU (3-15 points) & 5 & 2.0 & $3-14$ & 6 & 2.0 & $3-14$ & 5 & 2.3 & $3-10$ & 6 & 2.5 & $3-14$ & 5 & 1.8 & $3-11$ \\
\hline AI (3-15 points) & 10 & 2.0 & $3-15$ & 10 & 2.0 & $3-15$ & 11 & 2.0 & $4-15$ & 10 & 1.5 & $4-15$ & 10 & 2.8 & $3-15$ \\
\hline PL (3-15 points) & 10 & 1.1 & $3-15$ & 10 & 2.0 & $3-15$ & 10 & 1.0 & $5-14$ & 10 & 1.5 & $3-15$ & 10 & 1.0 & $5-13$ \\
\hline ET (3-15 points) & 7 & 2.0 & $3-15$ & 7 & 2.0 & $3-15$ & 7 & 2.0 & $5-15$ & 7 & 3 & $3-15$ & 8 & 2.0 & $3-15$ \\
\hline DI (3-15 points) & 8 & 2.0 & $3-15$ & 8 & 1.5 & $3-15$ & 8 & 1.8 & $4-14$ & 8 & 2 & $3-15$ & 8 & 1.8 & $4-14$ \\
\hline CA (3-15 points) & 9.5 & 2.1 & $3-15$ & $8 * *$ & 1.5 & $3-14$ & 12 & 2.0 & $3-15$ & 10 & 2 & $3-15$ & 9 & 1.8 & $3-15$ \\
\hline BP (3-15 points) & 4 & 1.5 & $3-13$ & $4 *$ & 1.5 & $3-13$ & 3 & 0.5 & $3-9$ & 3 & 1.5 & $3-13$ & 4 & 1.0 & $3-13$ \\
\hline NRS $(0-10$ points $)$ & 7 & 2.5 & $0-10$ & $5 *$ & 2.5 & $0-10$ & 7 & 0.5 & $1-10$ & 7 & 2.5 & $0-10$ & 7 & 1.5 & $0-10$ \\
\hline
\end{tabular}

M: median; QD: quartile deviation; IG: information gathering; GU: giving up; AI: affirmative interpreting; PL: planning; ET: evasive thoughts; DI: diversion; CA: catharsis; BP: buck passing; NRS: numerical rating scale of stress reactions. ${ }^{*} \mathrm{p}<0.05$; ${ }^{* *} \mathrm{p}<0.01$

Table 2. Spearman's correlation coefficients between all variables of interest when controlling for age, gender, and school year

\begin{tabular}{lcccccccc}
\hline & \multicolumn{7}{c}{ Tri-axial coping scale } \\
\hline & IG & GU & AI & PL & ET & DI & CA & BP \\
\hline GU & -0.01 & - & & & & & & \\
AI & 0.15 & -0.13 & - & & & & & \\
PL & $0.39^{* *}$ & -0.20 & $0.25^{*}$ & - & & & & \\
ET & -0.14 & $0.25^{*}$ & $0.46^{* *}$ & 0.24 & - & & & \\
DI & 0.21 & -0.16 & $0.24^{*}$ & 0.15 & 0.11 & - & & \\
CA & 0.23 & -0.05 & 0.09 & -0.04 & 0.10 & 0.01 & - & - \\
BP & 0.01 & $0.46^{* *}$ & 0.08 & -0.13 & 0.07 & 0.11 & -0.21 & $-26^{*}$ \\
NRS & -0.07 & $0.26^{*}$ & $-0.28^{*}$ & -0.05 & -0.02 & -0.08 & 0.22 & 0.08 \\
\hline
\end{tabular}

$\mathrm{N}=68$. IG: information gathering; GU: giving up; AI: affirmative interpreting; PL: planning; ET: evasive thoughts; DI: diversion; CA: catharsis; BP: buck passing; NRS: numerical rating scale of stress reactions. ${ }^{*} \mathrm{p}<0.05$; ${ }^{* *} \mathrm{p}<0.01$

belonged to the severe stress reactions group (NRS $>7$ ). A significant logistic regression equation was obtained: $\log (\mathrm{p} /$ $(1-\mathrm{p}))=1.78+1.96$ (gender) $+0.30(\mathrm{BP})\left(\chi^{2}=13.02, \mathrm{df}=2, \mathrm{p}=0.00\right)$. The $95 \%$ confidence intervals of the partial regression coefficients for the constant, gender, and BP were 0.43-3.14, 0.76-3.17, and 0.05-0.54, respectively. The odds ratios for gender and BP were $7.12(\mathrm{p}<0.01)$ and $1.34(\mathrm{p}<0.05)$, respectively.

\section{DISCUSSION}

The median NRS score of the PTSs for stress reactions during clinical practice was 7 points (quartile deviation, 2.5 points). In addition, the median scores for the IG, AI, PL, and CA strategies were higher than those for the other strategies. This indicates that many PTSs tried to positively act and think during clinical practice to manage the stressors of clinical practice. This finding supports the findings of previous studies ${ }^{8,10)}$.

The NRS scores of female PTSs were significantly higher than those of male students; this is consistent with previous work in which the prevalence of stress in female medical students was higher than in male students in Saudi Arabia ${ }^{2}$. However, there is also literature providing contrasting evidence. For instance, Saxena reported that male first-year medical students in India reported more stress than female students ${ }^{3)}$. Therefore, future studies are needed to clarify gender differences in stress reactions during physical therapy clinical practice. In addition, the BP and CA strategy scores for male PTSs were significantly greater than those of the female PTSs. Thus, male PTSs avoided problems associated with clinical practice, whereas the female PTSs released pent-up emotions through a variety of ways.

In addition, Spearman's correlation coefficients were calculated to determine the relation between the coping strategies while controlling for age, gender, and year of study. The coefficients between IG and PL strategies, GU and BP strategies, and AI and ET strategies were high compared with the relations between the other strategies. Positive coping strategies were linked, including positive relations between IG and PL strategies and positive relations between GU and BP strategies. 
Furthermore, positive relations between antithetical strategies, such as AI and ET, were also observed. Therefore, PTSs appear to cope with problems concerning clinical practice with ambivalence.

In addition, avoidance coping has been related to lower levels of well-being in nursing students ${ }^{13)}$. In the present study, stepwise logistic regression analysis indicated that the use of BP strategies, which are similar to avoidance behaviors, was independently associated with severe stress reactions. Avoidance coping strategies, including the BP strategy, were not prevalent in the present cohort or in Al-Dubai's cohort ${ }^{4}$; however, BP strategies were significantly related to the degree of perceived stress reactions. In addition, gender was independently associated with severe stress reactions, and the effect was significant for women. Therefore, clinical practice educators and teachers should be aware that the use of BP strategies is a risk factor for having severe stress reactions during clinical practice and that female PTSs are at risk for having severe stress reactions during clinical practice.

The present study was cross-sectional in design; therefore, the changeability of the coping strategies of the PTSs during clinical practice was not examined. Therefore, longitudinal studies are needed to assess how and if coping strategies can change. Moreover, there were no differences in the frequency of coping strategies between third- and fourth-year PTSs. In addition, the age of the majority of the participants was related to the year of study. Thus, age and year of study were not examined as predictors of high or slight stress reactions.

While the study provides new information on the coping strategies of PTSs, there were two major limitations. First, the present study was conducted at a single physical therapist training facility. In addition to vocational colleges, junior colleges and universities also provide training for physical therapists in Japan. Therefore, it is unclear whether the findings of the present study are generalizable to PTSs in junior colleges or universities. The learning environment, including the curriculum, may influence student behaviors and cognition regarding problems that occur during clinical practice; these questions should be investigated in future studies. Second, stressors associated with clinical practice were not examined herein. Quantification or qualitative classification of stressors would provide a deeper understanding of the relationships among stressors, coping strategies, and stress reactions of PTSs during clinical practice.

In conclusion, the present study demonstrates that female physical therapy students and those students who use buck passing suffer from high stress reactions during physical therapy clinical practice. It may be useful to examine the coping strategies for problems associated with clinical practice longitudinally. In addition, it seems important to investigate the characteristics of behaviors and thoughts related to everyday events prior to physical therapy students beginning clinical practice.

\section{REFERENCES}

1) Sreeramareddy CT, Shankar PR, Binu VS, et al.: Psychological morbidity, sources of stress and coping strategies among undergraduate medical students of Nepal. BMC Med Educ, 2007, 7: 26. [Medline] [CrossRef]

2) Abdulghani HM, AlKanhal AA, Mahmoud ES, et al.: Stress and its effects on medical students: a cross-sectional study at a college of medicine in Saudi Arabia. J Health Popul Nutr, 2011, 29: 516-522. [Medline] [CrossRef]

3) Saxena Y, Shrivastava A, Singhi P: Gender correlation of stress levels and sources of stress among first year students in a medical college. Indian J Physiol Pharmacol, 2014, 58: 147-151. [Medline]

4) Al-Dubai SA, Al-Naggar RA, Alshagga MA, et al.: Stress and coping strategies of students in a medical faculty in Malaysia. Malays J Med Sci, 2011, 18: 57-64. [Medline]

5) Yoshida Y, Asaumi Y, Nakano S, et al.: A basic study on the stress of physical therapy students faced with clinical training. J Jpn Phys Ther Assoc, 2014, 41: 94-95 (in Japanese).

6) Matsumoto N, Moriya K, Takeda H: Basic study of the immune system before and after the clinical practice and the personality. Hokkaido Rehabil, 1998, 26: 23-27 (in Japanese).

7) Lazarus RS, Folkman S: Stress, Appraisal, and Coping. New York: Springer, 1984

8) Kamimura H, Kageyama T: Stress coping profile and stress associated with practical training among pharmacy students. Job Stress Res, 2012, 19: 383-387 (in Japanese).

9) Kamimura E, Ebihara Y, Satou K, et al.: A validation of three-dimensional model of coping response and the development of the tri-axial coping scale (TAC24). B Couns Sch Psychol, 1995, 33: 41-47 (in Japanese).

10) Tateishi K, Tateishi N: A study of occupational therapy students' stress coping in the term of clinical practice. J Kyusyu U Health Welf, 2005, 6: 199-203 (in Japanese).

11) Higuchi D, Echigo A: Rigakuryouhoujissyuusei ni okeru sutoresutaishohouryakushakudo (TAC-24) no shinraisei no kenshou. P Jpn Soc Phys Ther Educ, 2015, 16 (in Japanese).

12) Shimizu H, Murayama A, Daibo I: Analyzing the interdependence of group communication (1) —application of hierarchical analysis into communication data-. IEICE Tech Rep, 2006, 106: 1-6 (in Japanese).

13) Gibbons C, Dempster M, Moutray M: Stress, coping and satisfaction in nursing students. J Adv Nurs, 2011, 67: 621-632. [Medline] [CrossRef] 